\title{
Cybernetic Approach of the "K'na" Dance: The Construction of Ethnic and National Identity in Nea Vyssa, Thrace, Greece
}

Eleni Filippidou

Ph.D. holder, School of Physical Education and Sports Science, National and Kapodistrian University of Athens, Greece, Athens

Maria Koutsouba

Associate professor, School of Physical Education and Sports Science, National and Kapodistrian University of Athens, Greece, Athens

Vassiliki Lalioti

Assistant Professor, Department of music studies, National and Kapodistrian University of Athens

\section{Vassilis Lantzos}

Assistant Professor, School of Physical Education and Sports Science, National and Kapodistrian University of Athens, Greece, Athens

Doi: $10.2478 / \mathrm{mjss}-2018-0022$

\begin{abstract}
The research field of this project is the area if Greek Thrace, which is a great geopolitical-cultural unity that was divided - due to political process - in three subareas that were distributed to three different countries: Bulgaria, Turkey and Greece. A dance happening that took place before the lining of the boundaries to date in the Greek and Turkish Thrace is that of "K'na". "K'na" is a female dance happening which is danced to date by the people of both areas in spite of their religious beliefs, social - economic and cultural development. The purpose of this project is to study the different expressions of this dance in Nea Vyssa and examine if these are related to matters of search and conformation of ethnic and national identity of this group under the terms of the social cybernetics. Data was gathered through the ethnographic method as this is applied to the study of dance and the interpretation of the data was based on the theoretical visuals of the social-cybernetic according to the inspection model of identity that Burke proposed. From the data analysis, we established that the dance of "K'na" in Nea Vyssa constructs and reconstructs not only the ethnic but the national identity of the groups who use them in order to react to the messages they receive via the communication with "the important others".
\end{abstract}

Keywords: greek traditional dance, socio-cybernetic, identity control theory, "k'na" dance event

\section{Introduction}

When studying culture, the term identity is often used. This term stands in the epicenter of contemporary thought and reflects inside the various meanings and usages attributed to it many of these ideas and conditions have determined the appearance of the modern world of today. The meaning of identity is directly connected with communication. According to Pashalidi (2000), 
communication is a significant function for a human being as it consisted of a basic element for the conformation of human societies and the creation of civilizations. Therefore, communication not only provides a social sense to people and a social group but also a sense that they belong to a cultural and social unity in other words to an identity (Vrizas, 2005). The Hecht et al regard communication as a way of creating identity. In other words, the Hecht et al. express that identity is a communicative structure. An identity is structured when people of groups communicate, that is to say, interact with each other. In this way the people involved or the groups internalize their reactions or opinions of "others" during this correlation of interactions (Watzlawick, Beavin, \& Jackson, 1967) and they, in turn, express and response to "others" by featuring their identity.

According to the cybernetic tradition of communication, when two people communicate, they define their relation by the ways they interact (Watzlawick, Beavin, \& Jackson, 1967). In the cybernetic approach, the relations that are produced in a group consist of interactive standards, in which words and actions of a person influence the reactions of others (Littlejohn \& Foss, 2012). The people that belong to a group constantly adapt their actions to the reactions of "others" based on the feedback they receive from them. Therefore, within the realms of the cybernetics, communication means a system of variables that affect one another, shape and control the temperament of the whole system and as every organization/entity they achieve balance and change.

Taking all the above into consideration, one can comprehend that in the cybernetic model of communication particular emphasis is placed not on this same message but on the aims that are pursued with the transmission of it (McQuail \& Windahl, 1993), and the relations that are shaped from the accomplishment of the aims among the communicating groups. Based on the above we could say that cybernetics consists of the stem of the meaning of identification either individually or collectively.

The research field of this project is the area in Greek Thrace, which is a great geopoliticalcultural unity that was divided - due to political process - in three subareas that were distributed to three different countries: Bulgaria, Turkey and Greece. A dance happening that took place before the lining of the boundaries to date in the Greek and Turkish Thrace is that of "K'na". "K'na" is a matrimonial dance happening which is danced to date by the people of both areas in spite of their religious beliefs, social - economic and cultural development. The purpose of this project is to study the different expressions of this dance in Nea Vyssa and examine if these are related to matters of search and conformation of ethnic and national identity of this group under the terms of the social cybernetics.

\section{Methodology}

The methodological process consisted of three steps, namely data collection, analysis and interpretation. Data was gathered through the ethnographic method as this is applied to the study of dance (Buckland, 1999; Giurchescu \& Torp, 1991; Sklar, 1991, Gkefou-Madianou 1999; Koutsouba, 1999; Lydaki, 2001) and based on primary and secondary sources. Primary sources refer to data gathered through fieldwork that was carried out at the region of Thrace, and particularly at the community of Nea Vyssa from December 2005 up to July 2017. Primary sources refer to the data coming from in-situ research, through interviews (open-type questions for semistructured interview and unstructured interview), and the participant observation combined with simultaneous audio and video recording of the inhabitants of the community. Oral history was used as a method, through which everyday memory is projected as a quest of social history (Thomson 2002). The overall course of field research was performed by the dual experience of the local culture with reference both to the habitants of this particular community (carriers of the local culture), as well as to the researchers (Erixon 1967). Secondary sources refer to the review and use of the existing literature and was based on the principles of archival ethnography (GkefouMadianou, 1999; Stocking 1992) and historical research (Adshead \& Layson (198).

For the collection, presentation and analysis of the data the Geertz model of the "thick description" (2003) was used, while the recording of the different types of "K'na" dance, the dance notation system of Laban was used (Labanotation) (Hutchinson 1977, Koutsouba 2005) as well as 
the Laban System of effort and their comparison was made by the method of comparison (Holt, \& Turner, 1972; Ogurchov, 1983). Finally, the analytical meaning of "myself"/"someone else" and "us"/"others" (Gkefou-Madianou 1999) that signify the identity as a cultural and social structure were the means of making the voices the these people heard giving them the opportunity to become informative, while the interpretation of the data was based on the theoretical visuals of the socialcybernetic according to the inspection model of identity that Burke (1991ab) proposed.

\section{Data analysis}

\subsection{Nea Vyssa: History and ethnographic context}

Nea Vyssa is located low of Evros in the northeast lowlands of the county of Evros (see map), south of the old Greek town of Andrianoupoli which now belongs to Turkey (Filippidou 2010, 2018) with a population of 2805 residents. The residents are descendants of refugees of Bosna or Vosnohori of Bosnohori which was situated a few kilometers northeast of and very close to Andrianoupoli.

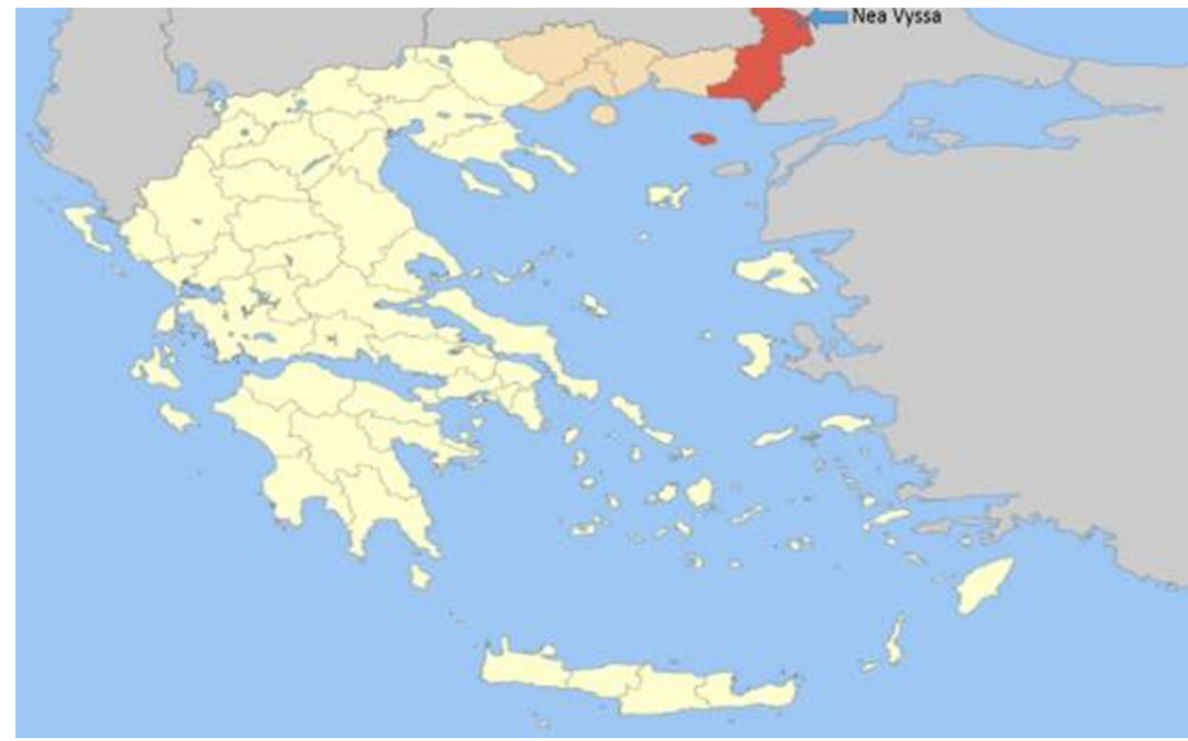

Map: Nea Vyssa and its geographic position in the regional unit of Evros

Source: https://upload.wikimedia.org/wikipedia/commons/e/ed/Nomos_Evrou.png

During the period of Turkish occupation and not known when, a small group of families appeared to be living in a small settlement $8-10 \mathrm{~km}$ southwest of Andrianoupoli on the edges of certain heights called Palati (Palace). The first resident of this settlement is said to have come from Italy when Andrianoupoli was the capital of the Turkish country and under the slavery of Sultan Murat (Filippidou 2010, 2018). Due to the danger of total extinction because of the constant threat of bandits this settlement was forced to relocate closer to Andrianoupoli where the danger decreased. In this area where the families went to, settlers from Bosnia had already resided.

The first residents of the settlement of Bosna united with Christian exiles, residents of "Palataki" settlement and other families that arrived there from different corners of the Ottoman empire such as Andrianoupoli, Filippoupoli, Chios, Varna, Saranta Ekklisies, Asia minor, Kappadokia, Pontus and other areas altogether creating Bosnohori (Filippidou 2010). There they lived until the destruction of Asia Minor. In 1923, after signing the Karagac protocol and the 
Lausanne Treaty, which set the borders and the people exchange, a piece of land in the West of Evros was given to Turkey which consisted of the settlements of Karagac, Bosna and Dormerta so as not to touch on the borders of Andrianoupoli and the railway in the West of Evros to remain in the Turkish grounds (Filippidou, 2010). The residents of Bosna had to therefore relocate $4 \mathrm{Km}$ south next to the Turkish-Greek borders and settle in the Achyrkioy settlement that was left in Greece. In 1920 it was renamed Stavlohori, in 1930 Achirohori and finally in 1932 Nea Vyssa (Filippidou, 2010).

\subsection{The dance event of "K'na" in Nea Vyssa.}

"K'nas" is a wedding dance particularly popular in the communities of Evros, especially those of Thrace origins which today belong to Turkey such as Nea Vyssa (Filippidou, 2010, 2018). This wedding dance takes place the night before the marriage at the house of the bride (Filippidou, $2010,2018)$. To be more specific, on that same night, the night before the wedding ceremony, a farewell party is held at the house of the bride as well as at the house of the groom. At the groom's house his family celebrates the last day of the soon to be groom but now unmarried lad. At the bride's house her family is more sentimentally intense due to it being the last night of the bride celebrating with her friends and family before moving to her husband's home. When all the guests arrive and the party begins the mother in law of the bride along with her relatives bring her "the Baxisia", in other words, her presents. Among those is a small plate with some henna. After they dance "the Baxisia" and then give them to the bride, they take "the Baxisia" from the relatives of the bride to give them to the groom by taking them to him and continuing the party there.

Later on, just before the end of the party, three newlywed girls whether by whole or half blood start preparing the "K'na" meaning the henna in a brass or earthenware plate, by using their right arms. They add water, flour and wine to this and place three lit candles in it. Next, they tie a red thread around the candles while during this preparation of the henna the relatives sing three songs suitable for this special occasion. The songs played are about emigration due to the fact that the bride is soon to leave her family and home and live with her husband and his family. After this slack preparation of the bride's ring finger and smallest one is painted by a female member of her family. They are painted up to the second phalanx and then tied with two white handkerchiefs or cloths. When this ritual is completed dancing begins with the first one in the line holding in his right hand the holy object of the ceremony which is the three lit candles (see picture) (Filippidou, 2010, 2018).

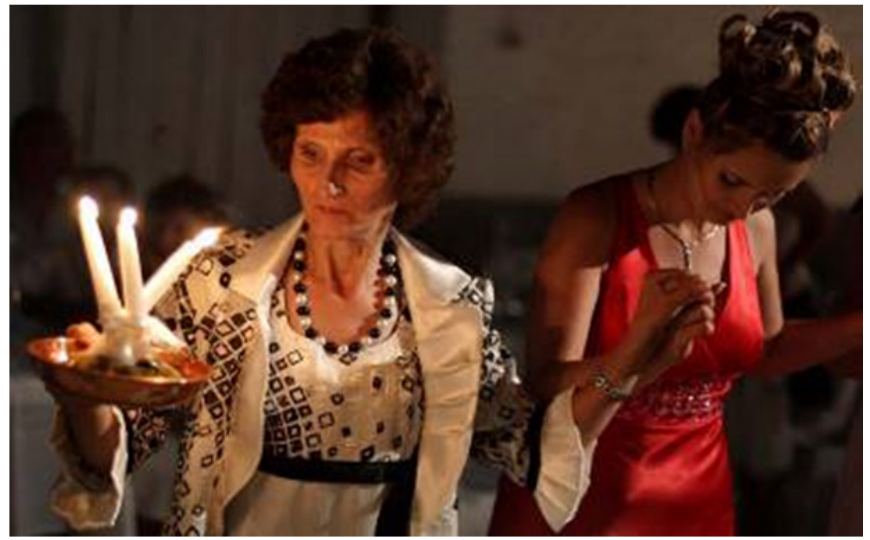

Picture: "K'na" Dance in Nea Vyssa 2010

In Nea Vyssa it is paradoxical that the "K'na" dance is a composite of three different dances. Two originate from the first refugees and the third originates from the second generation refugees (Filippidou, 2018). More specifically and according to informants one choreography regards the 
style of dance the residents of the community brought with them when coming to their new homeland This choreography consists of a unilateral style (see figure 1). The second choreography consists of a bilateral style (see figure 2) which were also danced by the first generation refugees. Finally, the third choreography refers to the second generation of refugees who replaced the first phrase of the "K'na" dance (see figure 3) (Filippidou, 2018).

"K'na" dance

first generation refugees

Lạbrnotation

Effort

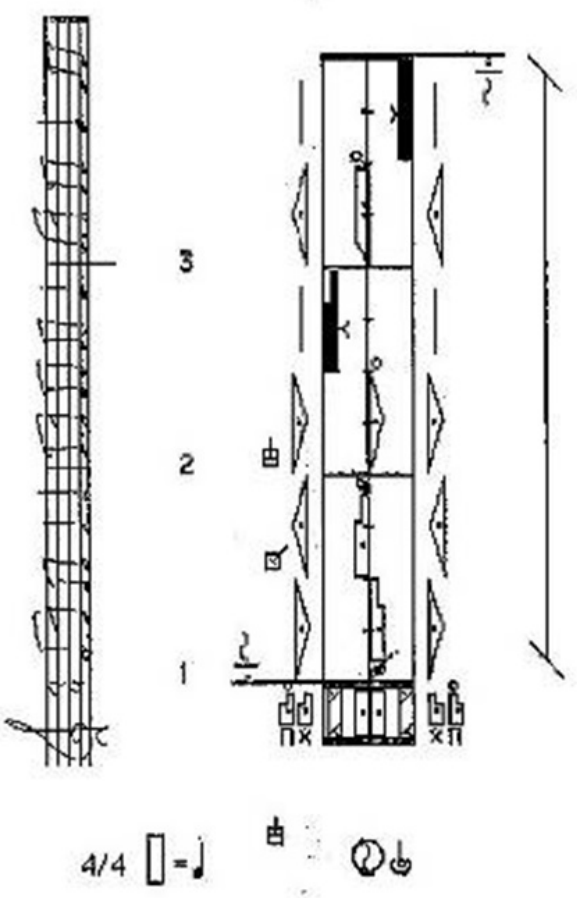

kn

Figure 1: "K'na" dance of first generation refugees 


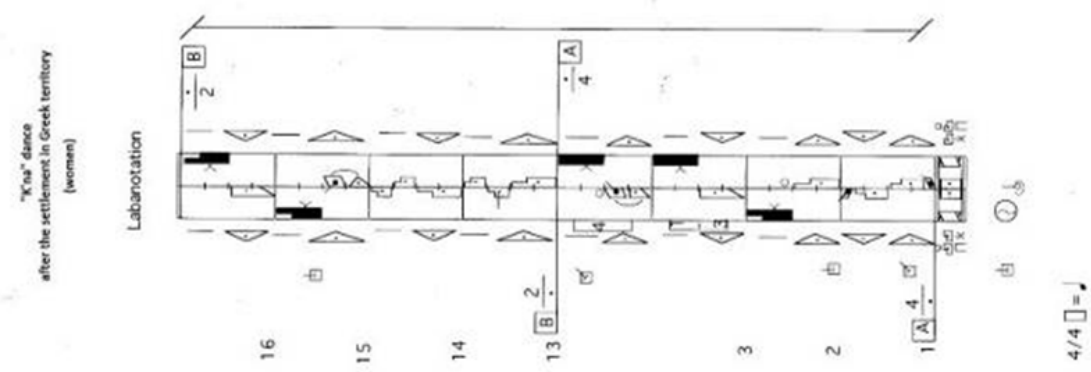

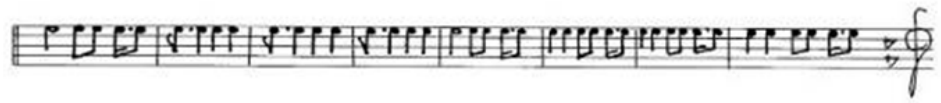

产

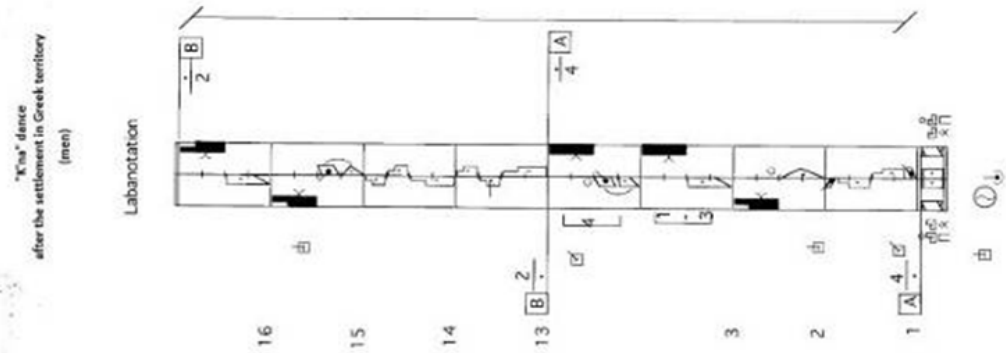

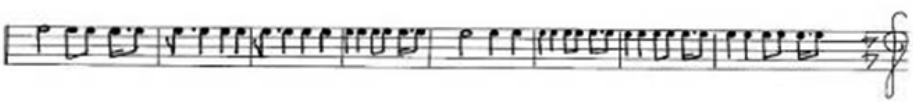

Figure 2: "K'na" dance after the settlement in Greek territory 


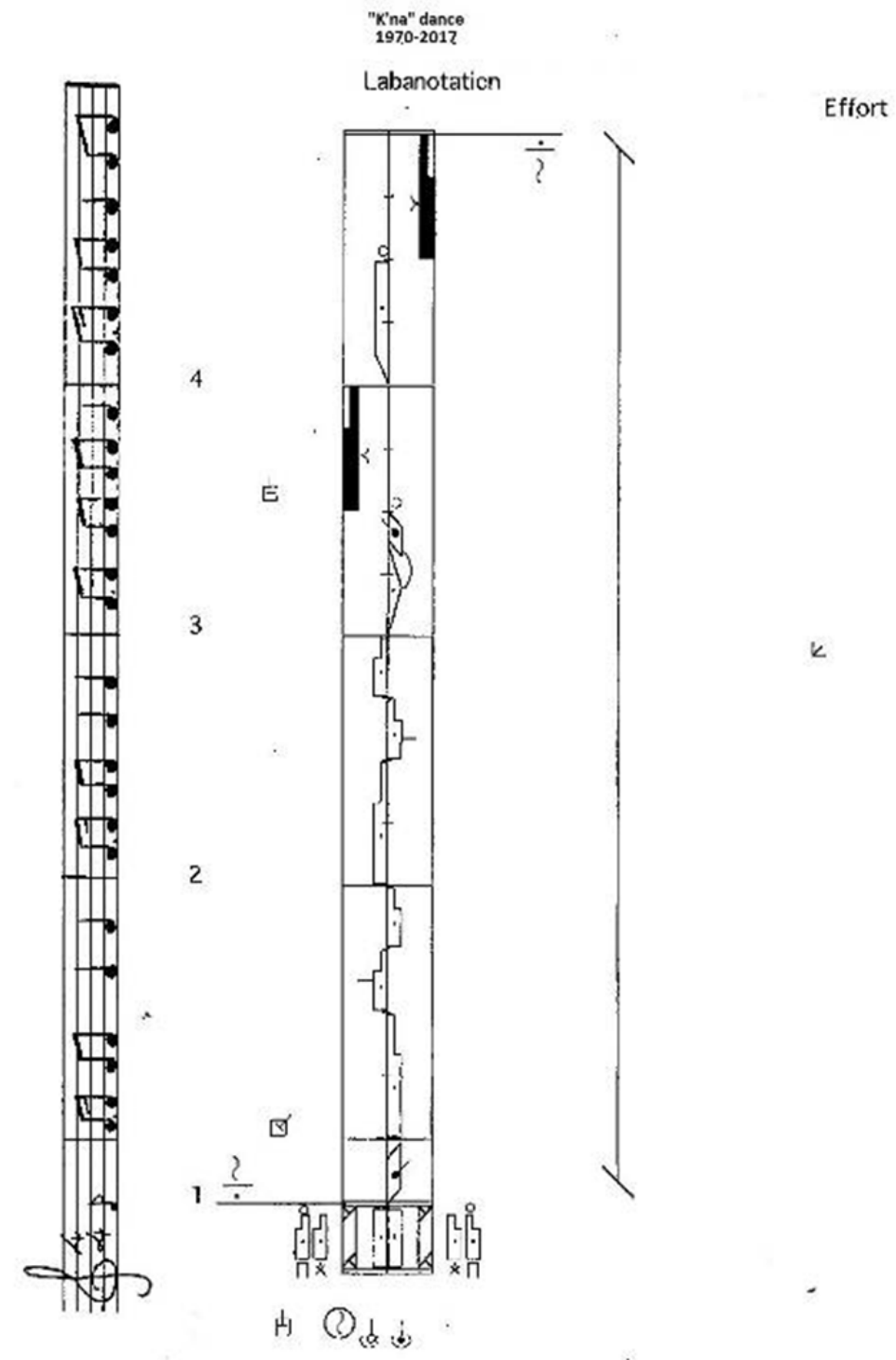

Figure 3: "K'na" dance during 1970-2017

The question is: why are there various expressions of the same dance in a community?

\subsection{Cybernetic construction of Nea Vyssa identity}

The area of Greek Thrace was a place of settlement of population from Ionia, Pontus, Kappadokia as well as from Bulgarian and Turkish Thrace. The biggest number of these people settled in the area of Evros (Filippidou, 2011). In all of the Greek area as well as in Thrace refugees were confronted with hostility by the locals. The Greek society had already shaped an opinion about the 
natives that lived in the Turkish areas which were not positive since the period of 1916. During that period the Labour centre of Athens was seeking to ban the hiring of refugees while the groups of conscripts of Dimitriou Gounari and loanni Metaxa were organizing the "pogrom" against the refugees while considering them as "Venizelikous", "supporters of Venizelos". (Livieratos, 1985).

In Evros the refugees were looked down on and called "Turks" and "Turkseeds". According to Livierato (1985:27) "along with more names that they were called, [...]. They were also in the daily ordinance by superior and inferior government executives.... ". Their dealing with this mainly had to do with rivalry concerning expropriation of land because the locals believed that the refugees were seeking after ownership of their properties. Because of this, coexistence was hard (Filippidou, $2011,2018)$. In the area of Evros this attitude also had to do with the place of origin of the refugees because the area bordered on Turkey which was considered an enemy nation (Filippidou, 2011).

A result of all the above was that both sides had feeling of introversion, rally and high rivalry and immediate action of changing the meaning of the term refugee into one of degrade, excluding them from social integration and accession. The effects of the above were the absence of smooth communication among the residents of the area. Meanwhile, communication is a basic component of an orderly cohabitation by allowing not only the people but also the groups to feel that they belong to a cultural-social unity or in other words to a group (Vrizas, 2005). However, the groups are component parts of broader groups that interact. The community of Nea Vyssa belongs to the group of refugees but it also belongs to the group of Evriton (from Evros). It boasts a Greek conscience and a particular local ethnic identity. For example, a resident of Nea Vissa has a varied social identity, identifying himself as an urban of Vissa, a Thrace refugee from Turkish Thrace, Evritis (from Evros) but also as a Greek therefore shaping levels of identity, an increased hierarchy where one encloses the other. These identities are in contact with one another, in other words, they are directly interdependent since each and every identity is confined due to its dependence on the other. The result of this interdependence is the creation of a standard identity of each group (Filippidou, 2018).

However, the standards of identities of these communities under study are in contradiction to the social environment of Thrace. The natives of the area had placed them in the social margin considering them as non-natives of Thrace, Evros or Greece. As follows the natives gave them a substandard identity in order to make them go away and take advantage of the exchangeable properties which they considered as being their own because of the fact of being in their land (Filippidou, 2018). Thus, the term "refugee" became a synonym for "inferiority" along with ethnic national divergence.

The attitude of the natives, which lasted for a long period of time, resulted in overflowing them with emotions of inferiority which collided with the standards of identity they previously had and their self-perception. According to Burke (1991b) when there is a discord in the incoming messages from the environment and the standard identity, a new parameter appears which that of sorrow is. This parameter compels the people to take action. This describes what happened to the refugees of Evros. This infliction by the locals who stigmatized and degraded their identity resulted in their change of behavior so as to restore their previous identity. In other words, instead of changing "others" opinions concerning them and their own negative feelings which were generated by the "others" they had to take action and change aspects of their identity. By doing so, they strived for influence on the behavior of the locals towards them and to also conform their perceptions to those of the "others" and their inferior standards.

One of the means which they used in order to alter "the others" feelings towards them was dance since it can express a certain content and abstract meaning generated by a particular type of cultural knowledge. (Koutsouba, 1999, 2002b) According to Manos (2004), dance is a strategy used by people when in process of structuring their identity. Hence, dance not only depicts but also shapes identity (Koutsouba, 2002b) 


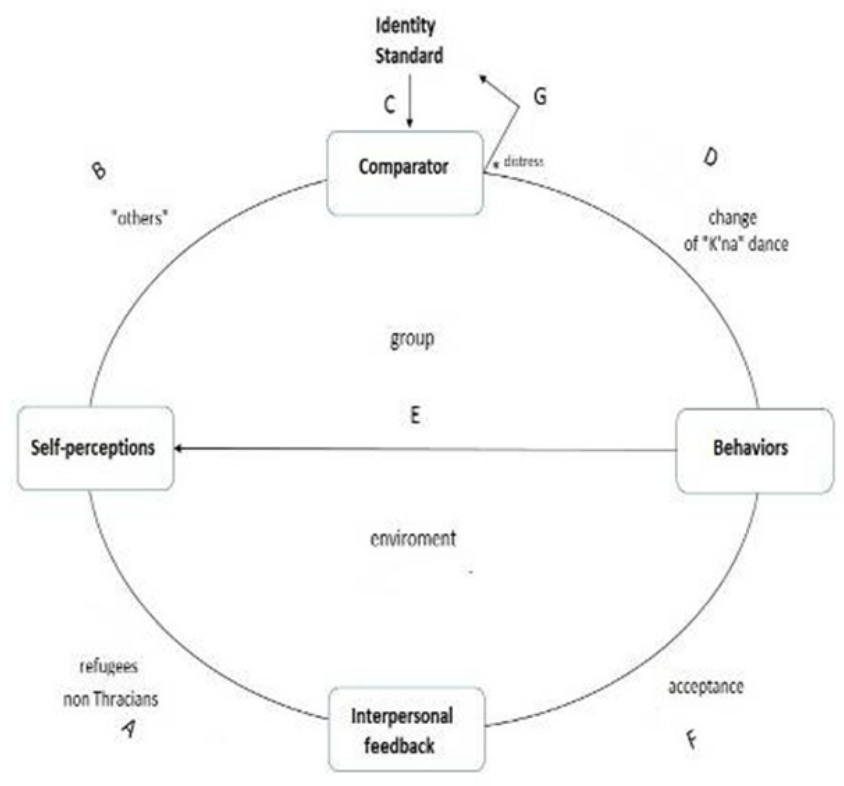

Figure 4. Identity control theory of Nea Vyssa

After receiving negative messages by their social environment they adapted the choreography of their compatriots into their own. By doing so they created new forms of dance which similar to those of the locals with the purpose of getting closer to them, settling their differences and changing the way they were treated by them. As follows the residents of Nea Vyssa added "K'na" to the dance which was a second dance phrase and formed a new choreographic composition. This new choreographic composition kept the initial "K'na" composition intact which they danced when they were in the area of Turkish Thrace but then they also added another dance phrase which we can also see in the dance repertoire of the natives (Filippidou, 2018).This move changed "the others" attitude towards them, they started resembling them and the feeling of inferiority slowly receded. This occurred because the locals were not still providing them with a stigmatized identity but treating them as equals and considering them as natives of Thrace, Evros or Greece. Due to the fact that hostility and opinion had changed so had the self-perception of the people of Nea Vissa. They were no longer in conflict with the standards of their identity and balance soon settled in their group as well (see figure 4) (Filippidou, 2018).

However, this balance was disrupted again. Their self-perception and, by extension, the standard of their identity, clashes with the standard of identity that "the junta of the colonels" impelled which lasted from 1967 to 1974 and which affected the whole Greek nation and identity. As in all oligarchic regimes, the national spirit and consciousness during this period were the targets of political authority. This led to creating a single cultural identity through the "GreekOrthodox tradition" (Karageorgou, 2001). The Greek-Orthodox tradition was a ploy of the newly established Greek nation in order to match the two conflicts of the past. More analytically the Greeks were seeking a match for the symbolic value of the ancient Greek culture which was so respected by Europe with their Byzantine tradition which was underestimated in order to create the base of the new nation-state (Kaloforidis, 2014; Molokotos - Liederman, 2003).

The political authority of that period supported on the "Greek-Orthodox tradition" made an attempt to form a single national identity. This single national identity should have been characterized by the unison of the Greek language and orthodox denomination and on the other hand the components of an identity of the past, in other words, having features of the ancient Greek 
civilization (Kaloforidis, 2014). The ancient Greek civilization as well as the Byzantine - as historical reference standards- supported the Greek national ideology for many centuries (Intzesiloglou, 1999). As follows, the new Greek nation was led to the "structure" of a national identity with the defining and standardization of a distinctive national tradition which was to be used as an exclusive and crystallized ideology (Mastorakis 2003-2004) "consanguineous and heterogeneous language and religion" were adopted which redeemed the desire for a homogeneous national identity based on ancient times. Whatever divergence in the components of this Greek formation was assessed as a national divergence and he who caused it considered as a "suspect" of national cohesion (Filippidou, 2010).

Supported on the imaginary standard of a common language, religion and origin, the Greek ruling class of that period along with the aid of all the powers of the government (army, education and church) was led to the creation of a Greek national identity through the "dogma of national unity" (Karageorgou, 2001:13). This common "Greek" conscience could not but be based on the public and obligatory education, which the junta also preserved. Via education there as an attempt to create a "given" tradition which would be developed by those who received this education. One of the political features that was chosen to mitigate the differences inside the nation and to make it official abroad as a national homogeneity was dance.

As follows, the "Pan-Hellenic" dances in the era of the junta prospered and were in the spotlight. Tsamiko and Kalamatiano dances were featured as national symbols (Koutsouba, 2014). By doing so, teaching "Pan-Hellenic" dances to students at school was adopted as a common national cultural identity (Fountzoulas, 2016). In the multicultural area of Evros, due to the multinational groups that lived there, the oligarchic regime of the junta integrated these dances in the educational system of Thrace. However, the local distinctiveness of each ethnic group and community became familiar and homogenized based on the idea of a cohesive national conscience. In place of them a "Panthrace" dance repertoire was created (Filippidou, 2010, 2011) which was imposed on those of other characteristics. In Nea Vyssa however, although the dance of "K'na" underwent changes in order to specify public opinion, still reserved features that depicted the local features of communities under study. These features could on the one hand be considered as "suspicious" of differentiation and on the other hand separated the residents of the area contrary to the aim of the junta which was the "national cohesion".

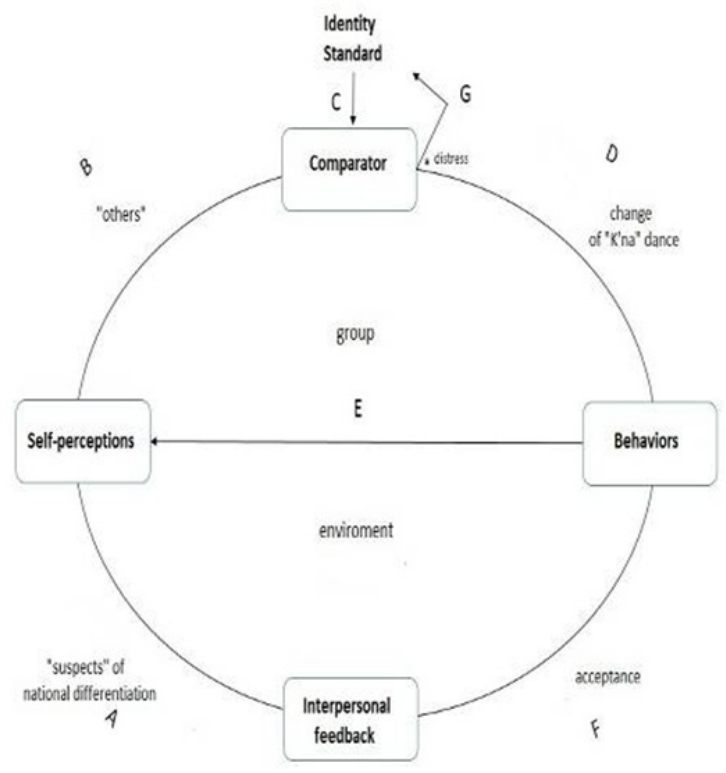

Figure 5. Identity Control Theory of Nea Vyssa from 1970 to 2017 
In order for these ethnic national groups under study to keep their harmony, while this cannot instantly be retrieved after any action, they tried self-regulating the perceived first quotes they received from the "others". As follows, they pursued the standards of identity that were imposed on them by dictatorship of the colonels and they adopted the dance style of the "Panthrace" repertoire which was created in favor of the Greek-Christian culture (Filippidou, 2018).

More analytically, the people of Nea Vyssa shunt the first dance phrase of "K'na" and use only the second which they had added in the choreography after their arrival in their new homeland. The second dance phrase which they had embraced by the local communities in order to resemble them with the ultimate aim of identifying their Greek-Thrace identity specified that of the mocked up one of the "Panthrace" repertoire. Thus, the people of Nea Vyssa changed their choreography of the "K'na" dance for the second time, extracting the dance pattern they used when living in Turkish Thrace and preserving that which they added when coming to Greek Thrace (see figure 5) (Filippidou, 2018).

Therefore, The identity of the people of Nea Vyssa did not remain stable this time either due to the fact that the residents of this community recognized their differentiation in the dance standards of "K'na" that the dictatorship of the colonels imposed and changed the choreography of the dance. This occurred because if they had kept the "K'na" patterns they would have been suspected of national differentiation, a fact that was contrary to the identity standards. In order to fit in and be in harmony with the internal standards of the opinion of "the others", in this case of Greek governance, they changed the choreography of "K'na" and adopted the quadruple and quartet pattern that they proposed. By doing so, they were considered by "the others" as Greeks of Thrace, a fact that coincided with their own self-reflection (Filippidou, 2018).

\section{Conclusions}

This project sheds light on the cybernetic structure of identity with the background of the wedding dance event of "K'na" as it takes place in the community of Nea Vyssa in Greek Thrace. The purpose of this study was to shed light on the diverse expressions of the dance of "K'na" boasts in Nea Vyssa and to examine if these associate with the matters of pursuit of ethnic and national identity of the group. For the purpose of determining this and editing theoretical matters, a combination of two parameters was used. Firstly, as a theoretical background the social- cybernetic approach was used in the same way as it was used in the theoretical model of Burke (1991) and secondly the analysis and study of the "K'na" dance itself was considered a requirement for the editing of theoretical matters. This combination of both parameters which was the record keeping and the analysis of the dance itself, as well as the analysis and interpretation based on the theoretical model of Burke (1991), comprised the structure of this study, providing a holistic approach towards this dance. The dance in this particular project played the role of a symbol and a "container" of meaning which can be used among others as a means of action and counteraction of the feedback they receive by "the others" and by extension to be seen as an indicator of the "structure" of this identity. This characteristic is attributed to its polysemous (Giurchescu, 1994, 2001 ) but also to its ability to communicate information in a non-verbal way (Lange, 1980; Koutsouba, 2003) which in turn make it possible for further symbolic deductions and generating "cultural knowledge" at the same time (Sklar, 1991).

From the data analysis, we established that the dance of "K'na" in Nea Vyssa forms and reforms not only the ethnic but the national identity of the groups who use them in order to react to the messages they receive via the communication with "the important others". In this way, by readjusting the dance of "K'na" in conjunction with the reactions of "the important ones", the people of Nea Vyssa adjust the perceived introductory information they receive in order to balance their interior standards with the assessments of the "others" for "themselves".

In more detail, the residents of Nea Vyssa adopted components and triunes of the local dance on their arrival, in order to acquire existence in the convey of the local villages of the area and to dispose of the degrading title "refugee" ascribed to them. However, later on, with the infliction of the junta of colonels, the choreography of "K'na" of all communities followed the dance standard the latter imposed so as not to be considered "suspicious" of national divergence. Through that number 
of actions, they tried to bring the standard of identity and the assessment of "the others" towards them in harmony. In this way, by mitigating and regulating the instability that emerged within the country by the messages they received by the "important others" aimed at the restoration of their former identity.

Therefore, the theoretical model of Burke (1991) is found to implement the national-cultural group of the people of Nea Vyssa accurately, displaying its effectiveness not only on a person but in groups as well. In spite of not using this model in the study of the dance, through the example of the event of the "K'na", as it is done by the above group, it was proven to be implemented in this case too. Combining the tools of the dance extensively with this model of inspection of identity, the possibility of investigating matters of figuration and reconstruction of a compiled group is given, which consists of a "structure" resulting from a process of communication and interaction with "other" groups.

Summarizing, based on all the above mentioned we can say that the feeling of "belonging" comprises of an active and continual process that allows the members of a group to act and exchange the meanings of their actions as reactions to the messages they receive in their environment. Hence, the "construction" of an identity results from a continuous procedure of selfregulation and self-control establishing that formulation of identity is a cybernetic sequence of steps.

\section{References}

Adshead, J., \& Layson, J. (eds.). (1986). Dance history. A methodology for study. London.

Buckland, Th. J. (1999). Introduction: Reflecting on dance ethnography. In T. Buckland (Ed.), Dance in the Field. Theory Methods and Issues in Dance Ethnography, (pp. 1-10). Great Britain: Macmillan Press Ltd.

Burke P. J. (1991). Identity processes and social stress. American Sociological Review, 56, 836-849

Burke P. J. (1991b). An identity theory approach to commitment. Social Psychology Quarterly, 54, $239-251$.

Erixon, S. (1967). Urgent-ethnological tasks. Ethnologia Europaea, 1,163-169.

Filippidou, E. (2010). Recycling the tradition: The dance in Nea Vyssa, northern Evros. Alexandroupolis: Municipality of Vyssa.

Filippidou, E. (2011). Dance and identity search. Acculturation and retribalization strategies of Inoi Gkagkavouz in Evros. Master thesis. Athens: University of Athens, Department of Physical Education and Sport Science.

Filippidou, E. (2018). Crossing the borders, uniting the people. Cybernetic dance approach at the "k'na" Thracian wedding event in Greece and Turkey. PhD thesis. Athens: University of Athens, Department of Physical Education and Sport Science.

Fountzoulas, G. (2016). Dance and politics: Positions and contrasts in the dance event "Gaitanaki" in Skala and in Dafni, Nafpaktia Greece. Unpublished Postgraduate thesis. Athens: TEFAA University of Athens.

Geertz, C. (2003). Thick description: Toward an interpretive theory of culture. In C. Geertz (ed.), The interpretation of cultures. Selected essays (pp. 1-30). New York: Basic Books

Gefou-Madianou, D. (1999). Culture and ethnography. From ethnographic realism to political criticism. Athens: Ellinika Grammata.

Giurchescu, A., \& Torp, L. (1991). Theory and methods in dance research: A european approach to the holistic study of dance. Yearbook for Traditional Music, 23, 1-10.

Giurchescu, A. (1994). The Power and the Dance Symbol and its Sociopolitical Use. In I. Loutzaki (ed.), Dance and its Socio-Political Aspects. Dance and Costume, Proceedings from the 17th Symposium of the Study Group on Ethnochoreology (pp. 15-23). Nafplion: Peloponnesian Folklore Foundation \& International Council for Traditional Music.

Giurchescu, A. (2001). The power of dance and its social and political uses. Yearbook for Traditional Music, 33, 109-121.

Holt T.R., \& Turner, E.J. (eds.). (1972). The methodology of comparative research. New York: The Free Press.

Hutchinson, A. (1977). Labanotation. The system of analyzing and recording movement. London: Dance Books.

Intzesiloglou, N. (1999). About the construction of collective identities. The example of national identity. In "We and the" others "(pp. 177-201). Athens: EKKE Typothito.

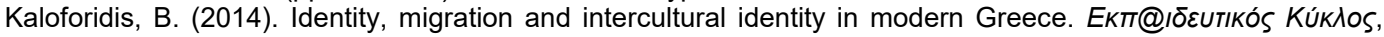
2(1), 199-282.

Koutsouba, M. (1999). 'Outsider' in an 'inside' world, or dance ethnography at home. In T. J. Buckland (Ed). Dance in the Field. Theory, Methods and Issues in Dance Ethnography (pp.186-195). London: Macmillan. 
Koutsouba, M. (2003). Identity and anthropological aspects of traditional dance. In N. Giftulas and others. (ed.), Arts II: Overview of Greek music and dance: Greek dance practice: traditional dance (Volume E, pp. 3345). Patras: Hellenic Open University

Koutsouba, I.M. (2005). Notation of dance movement. The passage from prehistory to the history of dance. Athens: Propobos.

Koutsouba, M. (2014). Places, dance(s) and 'realities'. Contexts and dance forms of Tsamikos dance in Greece. In E.I. Dunin \& C.E. Foley (eds.), Dance and Place \& Dance and Festival, Proceedings of 27th Symposium of the International Council for Traditional Music (ICTM) Study Group on Ethnochoreology (pp. 99-106). Ireland: The Irish Academy of Music and Dance, University of Limerick.

Lange, R. (1980). The development of anthropological dance research. Dance Studies, 4, 1-36.

Littlejohn, S.W. \& Foss, K.A. (2012). Human communication theories. Athens: Pedio.

Livieratos, D. (1985). Social struggles in Greece 1923-27. Athens: Alternative editions

Lydaki, A. (2001). Qualitative methods of social research. Athens: Kastaniotis.

McQuail, D. \& Windahl, S. (1993). Communication Models for the Study of Mass Communication. London: Longman.

Molokotos-Liederman, L. (2003) L'orthodoxie à l'école grecque. Unpublished paper and public lecture at the Ecole Pratique des Hautes Etudes, Paris, France, as part of a European conference on "Sciences des religions et systèmes de pensées".

Ogurchov, PA (1983). Comparative-historical method. In the Great Soviet Encyclopedia, (pp. 298-299). Athens: Akadimos.

Paschalidis, G. (2000). Cultural identity as a right and a threat. The dialectics of identity and the ambivalence of criticism. In Ch. Konstantopoulou, L. Maratou-Alibranti, D. Germanos, \& Th. Economou (Ed.), "We" and "Others". Reference to Trends and Symbols (pp. 73-83). Athens: Typothito.

Sklar, D. (1991). On dance ethnography. CORD Dance Research Journal , 23(1), 6-10.

Stocking, G. (1992). The Ethnographer's magic and other essays in the history of Anthropology. Madison: The Univervity of Wisconsin Press.

Thompson, P. (2002). Voices from the past: Oral history. Athens: Pletron.

Vrizas, K. (2005). Global communication. Political Identities. Athens: Gutenberg.

Watzlawick, P., Beavin, J. H., \& Jackson, D. D. (1967). Pragmatics of human communication: $A$ study of interactional patterns, pathologies, and paradoxes. New York: Norton. 